\title{
Short communication: Effect of milk and milk containing Lactobacillus casei on the intestinal microbiota of mice
}

\author{
Xiaochen Yin, Yinzhuo Yan, Eun Bae Kim, ${ }^{1}$ Bokyung Lee, and Maria L. Marco ${ }^{2}$ \\ Department of Food Science \& Technology, University of California, Davis 95616
}

\begin{abstract}
BALB/c mice were fed milk or Lactobacillus casei BL23 in milk for $14 \mathrm{~d}$ and fecal samples were collected at $\mathrm{d} 0,4$, and 7 as well as 1 and $8 \mathrm{~d}$ after the last administration. According to high-throughput DNA sequencing of the $16 \mathrm{~S}$ rRNA genes extracted from the fecal microbiota, the bacterial diversity in the fecal samples of all mice increased over time. After $14 \mathrm{~d}$ of administration, the consumption of milk and milk containing L. casei BL23 resulted in distinct effects on the microbial composition in the intestine. Specifically, the proportions of bacteria in the Lactobacillaceae, Porphyromonadaceae, and Comamonadaceae were significantly higher in mice fed the L. casei BL23-milk culture compared with one or more of the other groups of mice. The relative amounts of Lachnospiraceae were higher and Streptococcaceae were lower in mice fed milk alone. The changes were not found at d 4 and 7 during milk and $L$. casei feeding and were no longer detected $8 \mathrm{~d}$ after administration was stopped. This study shows that consumption of milk or probiotic L. casei-containing milk results in non-overlapping, taxa-specific effects on the bacteria in the distal murine intestine.
\end{abstract}

Key words: gut microbiota, dairy, probiotic, bacterial diversity

\section{Short Communication}

Bacteria colonizing the digestive tract confer important functions in human health and disease (Clemente et al., 2012). The composition and functional attributes of those bacterial inhabitants can be influenced by a variety of factors, including diet, age, genetics, medication, and health status (Lozupone et al., 2012). For example, dramatic differences in gut microbiota occur among individuals consuming globally distinct diets (e.g., high fat/high sugar vs. low fat/high fiber; Wu et

Received September 10, 2013.

Accepted December 24, 2013.

${ }^{1}$ Current address: Department of Animal Products and Food Science, College of Animal Life Sciences, 9 Kangwon National University, Chuncheon, Kangwon-do, 200-701, Republic of Korea.

${ }^{2}$ Corresponding author: mmarco@ucdavis.edu al., 2011). Diets modulated in single compounds (e.g., prebiotics, resistant starch, and alcohol) also affect bacterial activity and composition (Gibson et al., 2004; Bull-Otterson et al., 2013; Tachon et al., 2013).

Presently, the effects of individual foods and beverages on the structure of the intestinal microbiome are largely unknown and limited to foods such as fiber-rich fruit and vegetables (Li et al., 2009; Shinohara et al., 2010) and beverages containing polyphenols (Jaquet et al., 2009; Moco et al., 2012). An understanding of whether the regular consumption of specific foods (and beverages) alters the intestinal microbiome in distinct ways should yield novel insights into the role of those dietary constituents on health. Individual whole foods are of interest because these products commonly contain a variety of proteins, carbohydrates, and lipids that likely exert effects in concert rather than as individual nutrients. Bovine milk is one such product that is consumed in large quantities and recommended as a part of a healthy diet. Milk and dairy products contain a variety of macromolecular nutrients (proteins, FA, carbohydrates, and so on) and bioactive compounds (calcium, oligosaccharides, lipids, and so on; Mills et al., 2011). At present, the influence of milk and dairy products on the intestinal microbiome has only been studied in infants as a comparison to breast milk (Chichlowski et al., 2011; Tannock et al., 2013).

Certain dairy products also contain added bacterial cultures intended to confer health benefits in the gut. These bacteria are termed probiotics and numerous clinical and animal studies have demonstrated the potential for probiotics in the prevention and treatment of a variety of conditions at intestinal and extraintestinal sites (Sanders et al., 2013). Although probiotics are transient residents of the mammalian gut, these bacteria are able to adapt to conditions in the human intestine (Marco et al., 2010) and persist for several days or weeks after consumption (Saxelin et al., 2010; Smith et al., 2011). Previous studies have indicated that ingestion of probiotic bacteria does not result in global and long-lasting changes to the intestinal microbiome of healthy adult human individuals (McNulty et al., 2011; Kim et al., 2013; Lahti et al., 2013). Notably, these studies did not account for potential separate effects of 
A

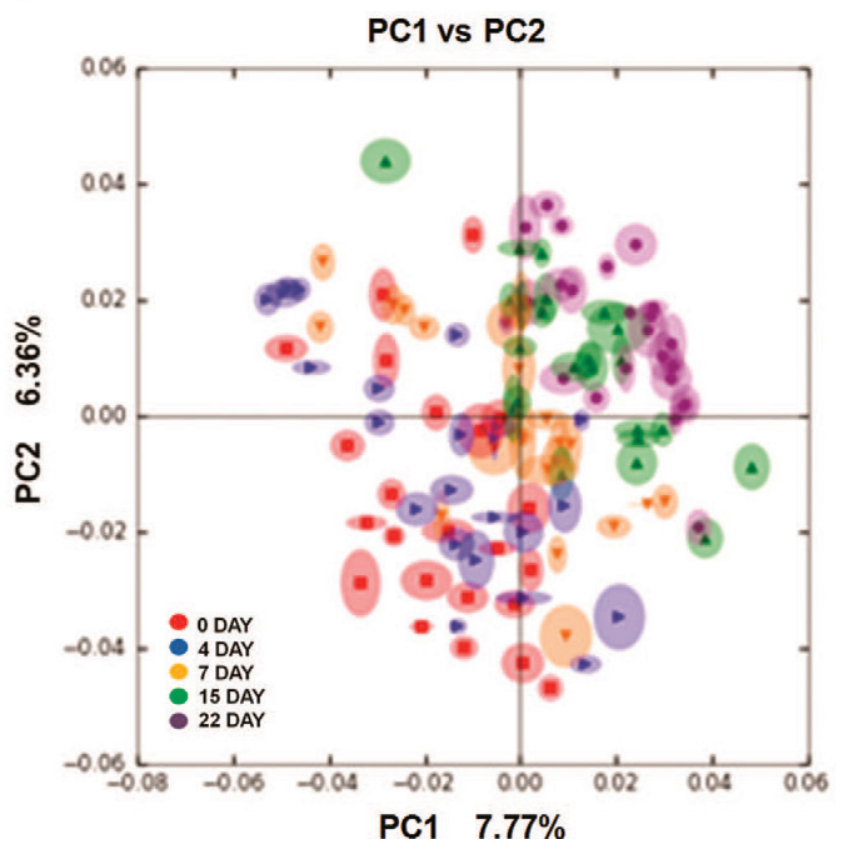

B

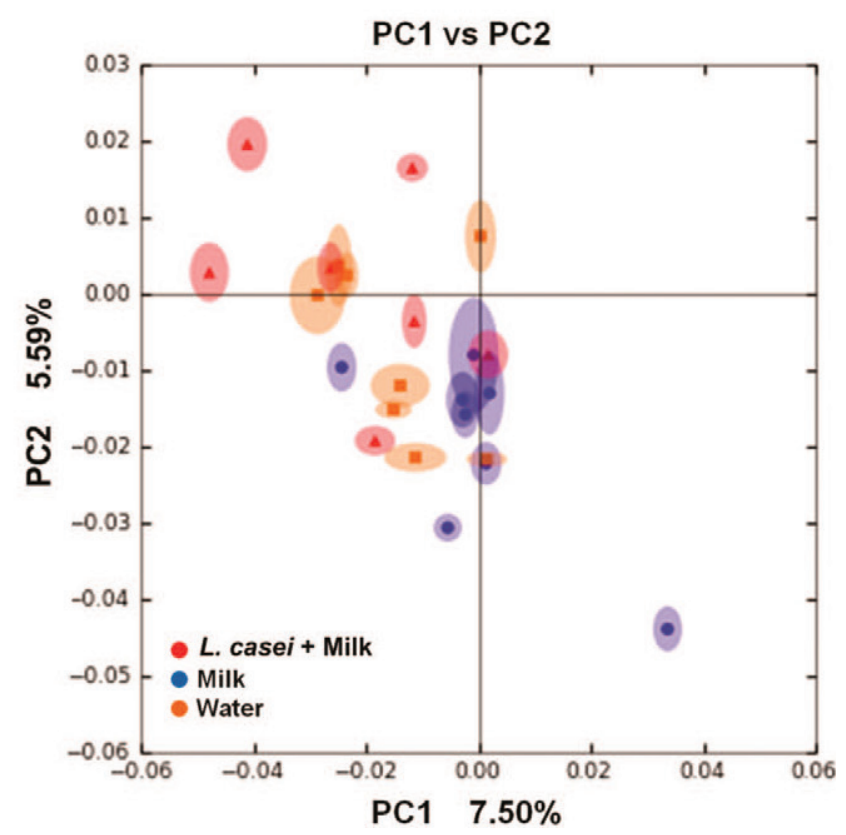

Figure 1. Temporal and treatment effects on the intestinal microbiota of mice. Principal coordinates (PC) analysis of the unweighted UniFrac metric for fecal microbiota collected at multiple time points (A) and at d 15 (B) of mice fed acidified milk, milk containing Lactobacillus casei BL23, or supplemental water.

the food delivery matrix on the intestinal microbiota nor was bacterial diversity examined at a high sequencing depth (McNulty et al., 2011; Kim et al., 2013).

In this study, we examined the influence of milk and milk containing Lactobacillus casei BL23 on the gut microbiota of conventionally raised, healthy mice. Lactobacillus casei strain BL23 was selected because it is genetically similar to commercial $L$. casei strains incorporated into dairy products (Mazé et al., 2010) and was demonstrated to protect against intestinal inflammation (Rochat et al., 2007) and Listeria monocytogenes infection (Archambaud et al., 2012). In a protocol approved by the Institutional Animal Use and Care Committee, University of California, Davis (no. 15922), 24 female BALB/c mice (5 wk old) were acclimated to Research Diet D12079B (Research Diets Inc., New Brunswick, NJ; $4.7 \mathrm{kcal} / \mathrm{g}$; here referred to as a Western diet) for 1 wk. This diet was selected to reflect typical human diets because the majority of calories come from fat (41\%) and sucrose (43\%). For the subsequent $14 \mathrm{~d}$, mice were orally administered dietary supplements of L. casei BL23 (rifampicin-resistant, $5 \times 10^{7} \mathrm{cfu} / \mathrm{d}$ in $50-\mu \mathrm{L}$ aliquots) in milk (pH $5.56 \pm 0.29), 50 \mu \mathrm{L}$ of milk acidified with $10 \%$ lactic acid to the same $\mathrm{pH}$ as the L. casei-milk culture, or $50 \mu \mathrm{L}$ of sterile water $(\mathrm{n}=8$ mice per treatment group). On a per-weight basis, this volume of milk and amount of cells is equivalent to a serving of $150 \mathrm{~mL}$ of milk and $1.5 \times 10^{11} \mathrm{~L}$. casei cells consumed by a $60-\mathrm{kg}$ human adult per day. To simulate dairy products intended for human consumption, the milk and L. casei-milk culture were incubated at $4^{\circ} \mathrm{C}$ before administration. Freshly expelled fecal samples were collected at d 0,4 , and 7 during the intervention and 1 and $8 \mathrm{~d}$ after cessation of the milk and L. casei feeding (d 15 and 22 after the start of the feeding study, respectively). Viable L. casei BL23 amounts were consistently found at levels of $10^{5} \mathrm{cfu} / \mathrm{g}$ of feces $24 \mathrm{~h}$ after each administration and were no longer detected $8 \mathrm{~d}$ after L. casei BL23 feeding was stopped (Supplementary Figure S1; http://dx.doi.org/10.3168/jds.2013-7477).

Total fecal DNA was extracted by mechanical lysis followed by DNA purification with the QIAamp DNA stool mini kit (Qiagen Inc., Valencia, CA; Tachon et al., 2013). Barcoded primers F515 and R806 were used to amplify the 16S rRNA gene V4 regions (Bokulich et al., 2012), and pooled amplicons were sequenced according to the paired-end protocol on the Illumina GAIIx platform (Illumina Inc., San Diego, CA) at the UC Davis Genome Center (http://dnatech.genomecenter.ucdavis. edu/). Raw Illumina FASTQ files were demultiplexed and quality filtered with the software package Quantitative Insights Into Microbial Ecology (QIIME; Caporaso et al., 2010; split_libraries_fastq.py, parameter settings: -r 3 -p 0.75 -q 3 -n 0). High-quality sequences 


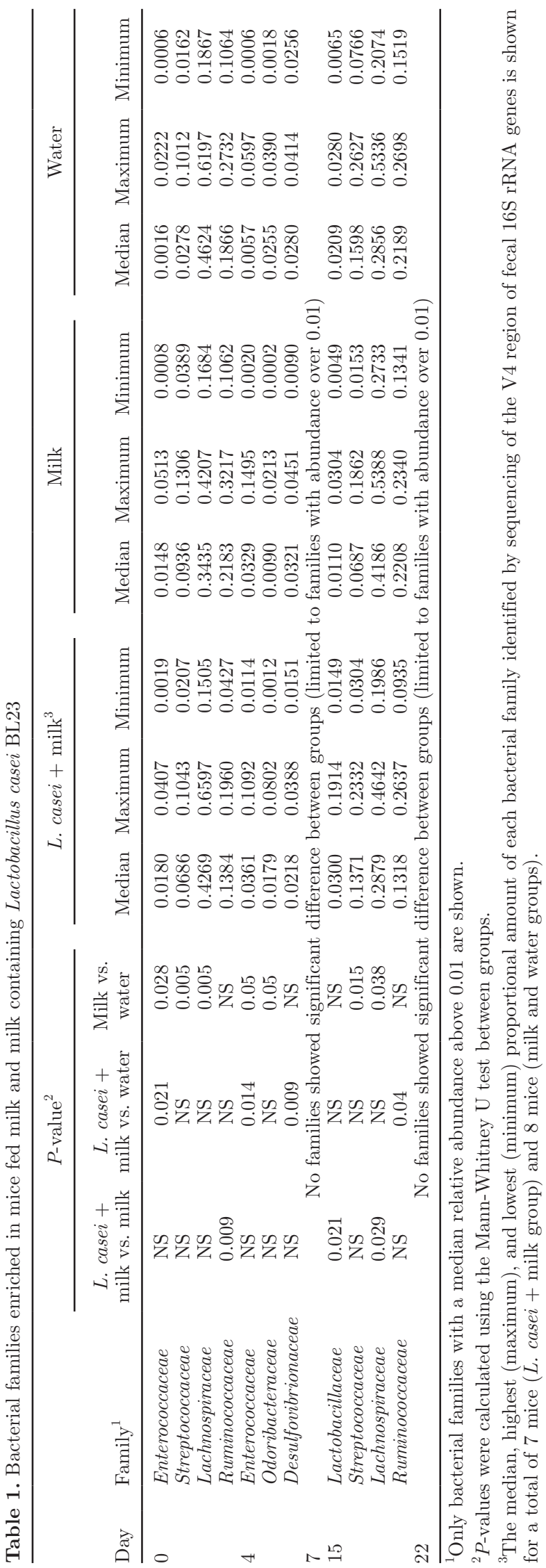

over 96 bp were selected from both ends and assembled together for each sample using an in-house Perl script. A fecal sample at time $t=0 \mathrm{~d}$ from a mouse fed $L$. case $i$ in milk yielded a very low number of reads and this animal was excluded from further analysis.

Operational taxonomic units (OTU) sharing at least $97 \%$ nucleotide identity were identified using a closedreference OTU picking process according to the Greengenes database (DeSantis et al., 2006) and then used for further analysis in QIIME. For taxonomic comparisons, nonparametric tests were performed using SPSS 17.0 (SPSS Inc., Chicago, IL) because not all of the taxa were normally distributed. The OTU metrics at d 15 were also examined by redundancy analysis performed in Canoco 4.5 for Windows software (Microcomputer Power, Ithaca, NY).

According to the observed species index (unique OTU in each sample), the bacterial diversity increased in the mouse intestine over the course of the 3 -wk study (d 0 vs. $22, P=0.027$ by the Mann-Whitney $\mathrm{U}$ test). Principal coordinates analysis of the unweighted UniFrac metric also revealed a clear shift in the fecal microbiota composition at each time point (Figure 1A). This finding indicates that the intestinal bacteria in the young mice examined here was dynamic. The increase in diversity might be due to a gradual adaptation of the intestinal bacterial communities to the high-fat and sucrose diet (Turnbaugh et al., 2008), normal mouse maturation and growth (Kibe et al., 2004), or stress due to handling (Dinan and Cryan, 2012). Similarly, Murphy et al. (2010) also found that the gut microbiota structure changed over a period of several weeks in mice fed a high-fat diet.

Bacterial diversity was also compared among the 3 treatment groups at each time point. Alpha-diversity indexes were not significantly different among mice fed acidified milk, L. casei in milk, or water according to Chao-1, Shannon, observed species, and phylogenetic distance (data not shown). Beta-diversity assessments using the principal coordinates analysis of the unweighted UniFrac metric also showed that the majority of the bacterial communities among the 3 groups were very similar (Figure 1B; Supplementary Figure S2; http://dx.doi.org/10.3168/jds.2013-7477).

Taxonomy comparisons were used to determine whether the fecal microbiota among the milk, L. casei BL23 in milk, and water treatment groups were distinguishable at the level of individual bacterial taxa. Prior to the initiation of supplemental feeding (d 0 ), the relative abundance of Enterococcaceae, Streptococcaceae, Lachnospiraceae, and Ruminococcaceae in the mouse stools differed between treatment groups (Table 1). These differences represent the natural variation in the microbiota of conventionally raised mice. The 


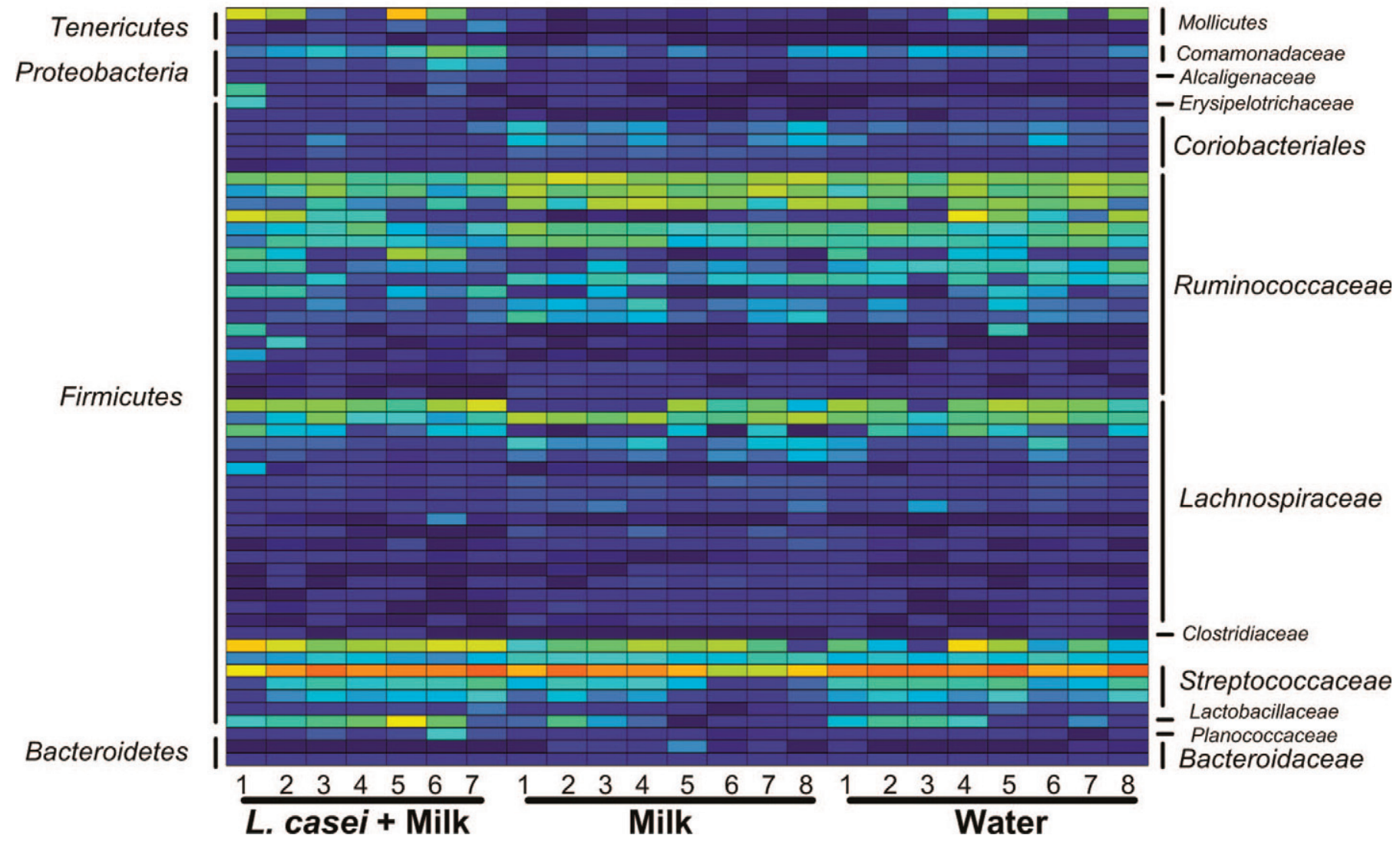

Figure 2. Relative abundance distribution of 60 operational taxonomic units (OTU) identified as key phylotypes in the fecal microbiota. Redundancy analysis was used, followed by the Kruskal-Wallis test $(P<0.05)$ to identify the key OTU based on the OTU metric at d 15 . Logarithmic (base 10) transformation was performed to show the relative abundance of the OTU. L. casei $=$ Lactobacillus casei.

groups of mice assigned to receive milk and L. casei in milk contained significantly higher proportions of Enterococcaceae compared with mice designated to receive water. Mice assigned to receive milk also harbored the highest proportions of Streptococcaceae and Ruminococcaceae (Table 1). In comparison, mice fed water were enriched in Lachnospiraceae (Table 1).

After feeding mice milk, L. casei in milk, or water for $4 \mathrm{~d}$, the proportions of Enterococcaceae remained significantly higher in mice receiving the L. casei and milk combination (Table 1). This difference was no longer found at d 7 and 15 (Table 1). At d 4, the relative amounts of Odoribacteraceae and Desulfovibrionaceae were also differently altered among the groups; however, significant differences in the proportions of those families were not found at other time points. Notably, the fecal microbiota were similar for all mice at $d 7$ of the study, indicating a normalization of the bacterial communities across treatment groups.

Feces collected on d 15, 2 wk after the initiation of the supplemental milk and L. casei feeding, showed the greatest number of changes in bacterial taxa since the start of the study (Table 1). Redundancy analysis also identified 60 OTU within 12 families that distinguished the microbiota between the 3 treatment groups (Figure 2 and Supplementary Table S1; http://dx.doi. org/10.3168/jds.2013-7477). Among these differences was a higher proportion of Lactobacillaceae in mice fed milk containing $L$. casei BL23 compared with those fed milk alone (Table 1 and Figure 3A), and these findings were confirmed by redundancy analysis (Figure 2). Although the increase in Lactobacillaceae might have been due to the $L$. casei fed to the mice, the number of viable $L$. casei BL23 cells constituted approximately less than $0.01 \%$ of the total number of bacteria in the mouse stools [approximately $10^{9}$ total cells/g of feces according to real-time PCR (data not shown)]. Hence, it is likely that other members of the Lactobacillaceae were also enriched in the mice. In contrast, the relative amounts of Ruminococcaceae were lowest in the mice fed $L$. case $i$ in milk and this difference was significant compared with the water-fed controls (Figure 3B). 
A

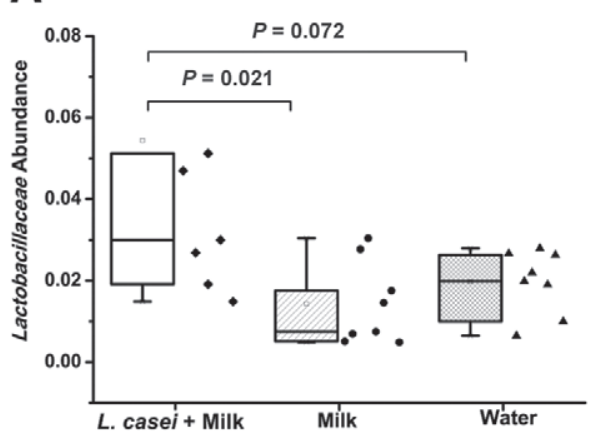

D

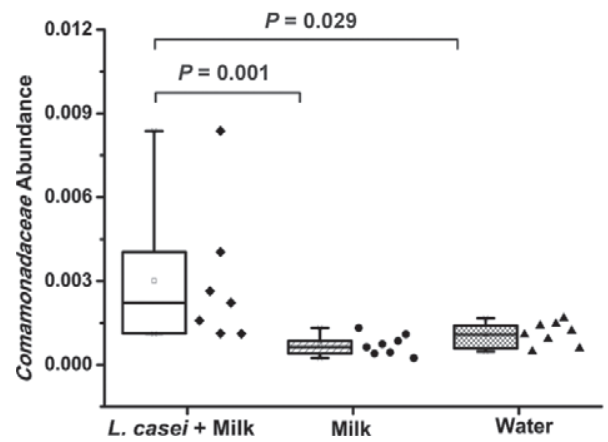

B

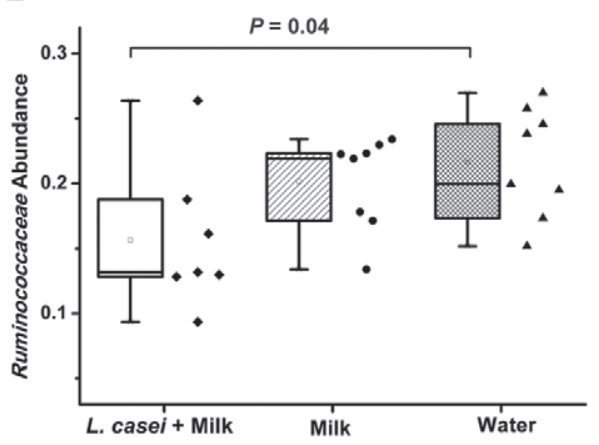

E

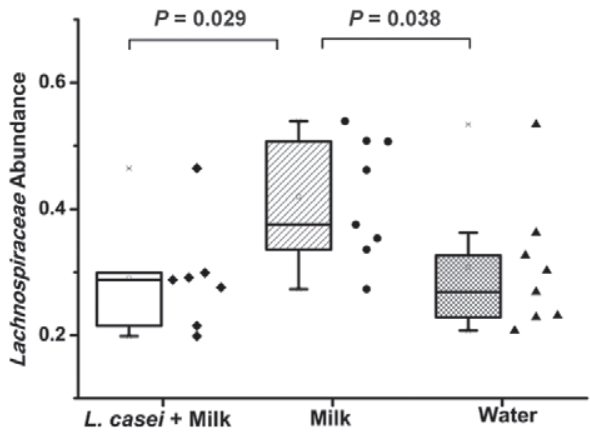

C

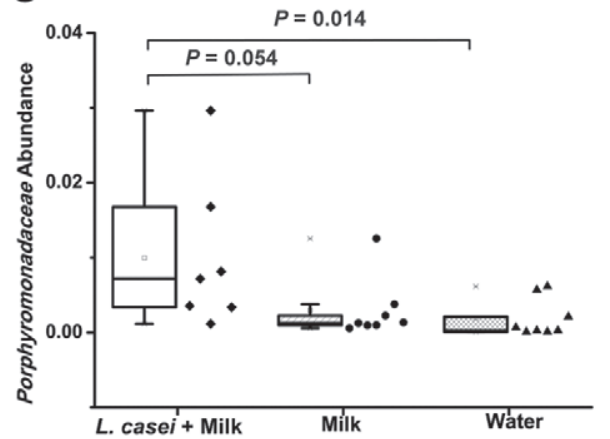

$\mathbf{F}$

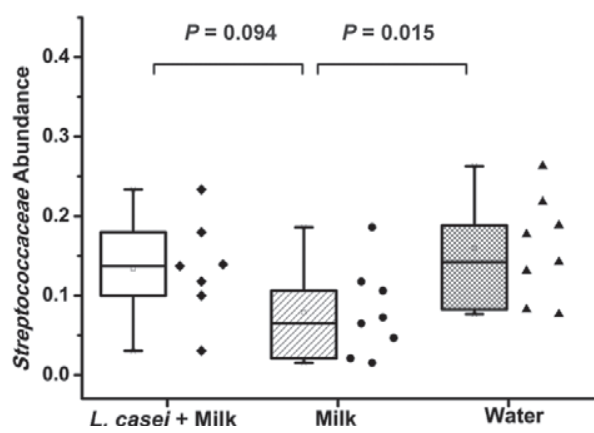

Figure 3. Bacterial families enriched in mice fed milk and milk containing Lactobacillus casei BL23 for 14 d. The proportions of Lactobacillaceae (A), Ruminococcaceae (B), Porphyromonadaceae (C), Comamonadaceae (D), Lachnospiraceae (E), and Streptococcaceae (F) are shown for mice $24 \mathrm{~h}$ after the last administration of $L$. case $i$ BL23 in milk, milk, or water. The lower boundary of the box is the 25 th percentile, the line within the box marks the median, and the upper boundary of the box indicates the 75th percentile. Whiskers (error bars) above and below the box indicate the 90th and 10th percentiles; $P$-values were calculated based on the Mann-Whitney $\mathrm{U}$ test between groups.

Members of the Porphyromonadaceae (Bacteroidetes phylum) and Comamonadaceae (Proteobacteria phylum) were also significantly enriched in the L. caseimilk fed mice (Figure 3C and D). Although the relative amounts of bacteria in these families were below $1 \%$, both contained specific genera specifically enriched in L. casei-milk fed mice and hence are discussed here. In particular, members of the Parabacteroides genus in the Porphyromonadaceae were in significantly higher proportions in $L$. casei-milk fed mice compared with water-fed controls (Supplementary Figure S3A; http:// dx.doi.org/10.3168/jds.2013-7477). Parabacteroides are members of the Porphyromonadaceae family and were previously found to be enriched in healthy volunteers compared with those with inflammatory bowel syndrome or ulcerative colitis (Noor et al., 2010) and in elderly people compared with young adults (Claesson et al., 2011). Among the Comamonadaceae, members of the Comamonas genus were enriched in mice fed L. casei BL23 in milk compared with mice fed milk alone (Supplementary Figure S3B; http://dx.doi. org/10.3168/jds.2013-7477). Comamonadaceae and OTU in this family were also found to increase in mice fed $L$. casei BL23 in milk at d 15 by redundancy analysis (Figure 2). This bacterial genus has been isolated from soil, water, as well as clinical environments, and Comamonas testosteroni was reported to degrade and consume steroids as sole-carbon sources (Horinouchi et al., 2010).

Milk alone also resulted in significant changes to the intestinal microbiota. Specifically, members of the Lachnospiraceae family were in greater proportions in mice fed milk compared with the other 2 groups of mice by taxonomic comparisons (Figure 3E) and redundancy analysis (Figure 2). Whereas the average proportional amounts of bacteria in Lachnospiraceae increased from d 0 in the milk-fed mice, the relative amounts of this family declined in the L. casei BL23- and water-fed groups. The Lachnospiraceae constitute a relatively large family of bacteria, the majority of which have yet to be cultured. Hence, specific genera increased in this family due to milk consumption were not identified by the sequencing methods applied here.

The average proportions of Streptococcaceae were lower in milk-fed mice; however, significance was only reached compared with the water-fed controls (Table 1, Figure 2, and Figure $3 \mathrm{~F}$ ). This family was significantly affected by milk consumption because mice in that treatment group harbored the highest relative proportion of Streptococcaceae at d 0 (Table 1). In particular, 
the relative amounts of Lactococcus members of this family were significantly reduced in mice fed milk (Supplementary Figure S3C; http://dx.doi.org/10.3168/ jds.2013-7477). Lactococcus has been consistently identified as an important member of the murine intestinal microbiota and was enriched in the intestines of obese mice (Benson et al., 2010; Ravussin et al., 2012). Although Lactococcus is commonly recognized as a dairy-associated microorganism with the capacity to consume lactose, lactose metabolism is commonly plasmid associated and not a defining feature of this species (Yu et al., 1996; Siezen et al., 2005).

One week after the cessation of feeding milk and $L$. casei, no significant differences were observed in the proportional amounts of bacteria in the mouse stools (Table 1). Hence, observable changes to the intestinal microbiota with consumption of milk and $L$. casei BL23 were transient and did not result in lasting effects, at least in the distal portion of the gut reported by assessments of fecal composition. Overall, this study is the first to show that (acidified) milk and milk-probiotic combinations confer modest and transient but still detectable and non-overlapping effects on the composition of the intestinal microbiota of mice. The results indicate that consuming milk alters indigenous bacterial populations in the mouse digestive tract in ways that are no longer detectable with the addition of a probiotic culture to the milk matrix. Although it remains to be shown whether this outcome would be found for human individuals with a long history of dairy consumption, the results here support investigations into elucidating the molecular mechanisms of milk and probiotic interactions with the microorganisms colonizing the digestive tract.

The DNA sequences were deposited in the GenBank Sequence Read Archive database (http://www. ncbi.nlm.nih.gov/Traces/sra) with accession number SRP022347.

\section{ACKNOWLEDGMENTS}

Funds for this study were provided by the National Dairy Council (Rosemont, IL) and administered by the Dairy Research Institute through the California Dairy Research Foundation (Davis, CA). We thank Sybille Tachon (Department of Food Science \& Technology, University of California, Davis) for her technical support with the mouse study.

\section{REFERENCES}

Archambaud, C., M.-A. Nahori, G. Soubigou, C. Bécavin, L. Laval, P. Lechat, T. Smokvina, P. Langella, M. Lecuit, and P. Cossart. 2012.
Impact of lactobacilli on orally acquired listeriosis. Proc. Natl. Acad. Sci. USA 109:16684-16689.

Benson, A. K., S. A. Kelly, R. Legge, F. Ma, S. J. Low, J. Kim, M. Zhang, P. L. Oh, D. Nehrenberg, K. Hua, S. D. Kachman, E. N. Moriyama, J. Walter, D. A. Peterson, and D. Pomp. 2010. Individuality in gut microbiota composition is a complex polygenic trait shaped by multiple environmental and host genetic factors. Proc. Natl. Acad. Sci. USA 107:18933-18938.

Bokulich, N. A., C. L. Joseph, G. Allen, A. K. Benson, and D. A. Mills. 2012. Next-generation sequencing reveals significant bacterial diversity of botrytized wine. PLoS ONE 7:e36357.

Bull-Otterson, L., W. Feng, I. Kirpich, Y. Wang, X. Qin, Y. Liu, L. Gobejishvili, S. Joshi-Barve, T. Ayvaz, J. Petrosino, M. Kong, D. Barker, C. McClain, and S. Barve. 2013. Metagenomic analyses of alcohol induced pathogenic alterations in the intestinal microbiome and the effect of Lactobacillus rhamnosus GG treatment. PLoS ONE 8:e53028.

Caporaso, J. G., J. Kuczynski, J. Stombaugh, K. Bittinger, F. D. Bushman, E. K. Costello, N. Fierer, A. G. Peña, J. K. Goodrich, J. I. Gordon, G. A. Huttley, S. T. Kelley, D. Knights, J. E. Koenig, R. E. Ley, C. A. Lozupone, D. McDonald, B. D. Muegge, M. Pirrung, J. Reeder, J. R. Sevinsky, P. J. Turnbaugh, W. A. Walters, J. Widmann, T. Yatsunenko, J. Zaneveld, and R. Knight. 2010. QIIME allows analysis of high-throughput community sequencing data. Nat. Methods 7:335-336.

Chichlowski, M., J. B. German, C. B. Lebrilla, and D. A. Mills. 2011 The influence of milk oligosaccharides on microbiota of infants: Opportunities for formulas. Annu. Rev. Food Sci. Technol. 2:331351.

Claesson, M. J., S. Cusack, O. O'Sullivan, R. Greene-Diniz, H. de Weerd, E. Flannery, J. R. Marchesi, D. Falush, T. Dinan, G. Fitzgerald, C. Stanton, D. van Sinderen, M. O'Connor, N. Harnedy, K. O'Connor, C. Henry, D. O'Mahony, A. P. Fitzgerald, F. Shanahan, C. Twomey, C. Hill, R. P. Ross, and P. W. O'Toole. 2011. Composition, variability, and temporal stability of the intestinal microbiota of the elderly. Proc. Natl. Acad. Sci. USA 108:4586-4591.

Clemente, J. C., L. K. Ursell, L. W. Parfrey, and R. Knight. 2012. The impact of the gut microbiota on human health: An integrative view. Cell 148:1258-1270.

DeSantis, T. Z., P. Hugenholtz, N. Larsen, M. Rojas, E. L. Brodie, K. Keller, T. Huber, D. Dalevi, P. Hu, and G. L. Andersen. 2006 Greengenes, a chimera-checked 16S rRNA gene database and workbench compatible with ARB. Appl. Environ. Microbiol. 72:5069-5072.

Dinan, T. G., and J. F. Cryan. 2012. Regulation of the stress response by the gut microbiota: Implications for psychoneuroendocrinology. Psychoneuroendocrinology 37:1369-1378

Gibson, G. R., H. M. Probert, J. Van Loo, R. A. Rastall, and M. B. Roberfroid. 2004. Dietary modulation of the human colonic microbiota: Updating the concept of prebiotics. Nutr. Res. Rev. $17: 259-275$.

Horinouchi, M., T. Kurita, T. Hayashi, and T. Kudo. 2010. Steroid degradation genes in Comamonas testosteroni TA441: Isolation of genes encoding a $\Delta 4(5)$-isomerase and $3 \alpha$ - and $3 \beta$-dehydrogenases and evidence for a $100 \mathrm{~kb}$ steroid degradation gene hot spot. J. Steroid Biochem. Mol. Biol. 122:253-263.

Jaquet, M., I. Rochat, J. Moulin, C. Cavin, and R. Bibiloni. 2009 Impact of coffee consumption on the gut microbiota: A human volunteer study. Int. J. Food Microbiol. 130:117-121.

Kibe, R., M. Sakamoto, H. Hayashi, H. Yokota, and Y. Benno. 2004 Maturation of the murine cecal microbiota as revealed by terminal restriction fragment length polymorphism and 16S rRNA gene clone libraries. FEMS Microbiol. Lett. 235:139-146.

Kim, S.-W., W. Suda, S. Kim, K. Oshima, S. Fukuda, H. Ohno, H Morita, and M. Hattori. 2013. Robustness of gut microbiota of healthy adults in response to probiotic intervention revealed by high-throughput pyrosequencing. DNA Res. 20:241-253.

Lahti, L., A. Salonen, R. A. Kekkonen, J. Salojärvi, J. Jalanka-Tuovinen, A. Palva, M. Orešič, and W. M. de Vos. 2013. Associations between the human intestinal microbiota, Lactobacillus rhamno- 
sus GG and serum lipids indicated by integrated analysis of highthroughput profiling data. PeerJ 1:e32.

Li, F., M. A. J. Hullar, Y. Schwarz, and J. W. Lampe. 2009. Human gut bacterial communities are altered by addition of cruciferous vegetables to a controlled fruit- and vegetable-free diet. J. Nutr. 139:1685-1691.

Lozupone, C. A., J. I. Stombaugh, J. I. Gordon, J. K. Jansson, and R. Knight. 2012. Diversity, stability and resilience of the human gut microbiota. Nature 489:220-230.

Marco, M. L., M. C. de Vries, M. Wels, D. Molenaar, P. Mangell, S. Ahrne, W. M. de Vos, E. E. Vaughan, and M. Kleerebezem. 2010. Convergence in probiotic Lactobacillus gut-adaptive responses in humans and mice. ISME J. 4:1481-1484.

Mazé, A., G. Boël, M. Zúñiga, A. Bourand, V. Loux, M. J. Yebra, V. Monedero, K. Correia, N. Jacques, S. Beaufils, S. Poncet, P. Joyet, E. Milohanic, S. Casarégola, Y. Auffray, G. Pérez-Martínez, J.F. Gibrat, M. Zagorec, C. Francke, A. Hartke, and J. Deutscher. 2010. Complete genome sequence of the probiotic Lactobacillus casei strain BL23. J. Bacteriol. 192:2647-2648.

McNulty, N. P., T. Yatsunenko, A. Hsiao, J. J. Faith, B. D. Muegge A. L. Goodman, B. Henrissat, R. Oozeer, S. Cools-Portier, G. Gobert, C. Chervaux, D. Knights, C. A. Lozupone, R. Knight, A. E. Duncan, J. R. Bain, M. J. Muehlbauer, C. B. Newgard, A. C. Heath, and J. I. Gordon. 2011. The impact of a consortium of fermented milk strains on the gut microbiome of gnotobiotic mice and monozygotic twins. Sci. Transl. Med. 3:106ra106.

Mills, S., R. P. Ross, C. Hill, G. F. Fitzgerald, and C. Stanton. 2011. Milk intelligence: Mining milk for bioactive substances associated with human health. Int. Dairy J. 21:377-401.

Moco, S., F.-P. J. Martin, and S. Rezzi. 2012. Metabolomics view on gut microbiome modulation by polyphenol-rich foods. J. Proteome Res. 11:4781-4790.

Murphy, E. F., P. D. Cotter, S. Healy, T. M. Marques, O. O'Sullivan, F. Fouhy, S. F. Clarke, P. W. O'Toole, E. M. Quigley, C. Stanton, P. R. Ross, R. M. O'Doherty, and F. Shanahan. 2010. Composition and energy harvesting capacity of the gut microbiota: Relationship to diet, obesity and time in mouse models. Gut 59:1635-1642.

Noor, S. O., K. Ridgway, L. Scovell, E. K. Kemsley, E. Lund, C. Jamieson, I. T. Johnson, and A. Narbad. 2010. Ulcerative colitis and irritable bowel patients exhibit distinct abnormalities of the gut microbiota. BMC Gastroenterol. 10:134.

Ravussin, Y., O. Koren, A. Spor, C. LeDuc, R. Gutman, J. Stombaugh, R. Knight, R. E. Ley, and R. L. Leibel. 2012. Responses of gut microbiota to diet composition and weight loss in lean and obese mice. Obesity (Silver Spring) 20:738-747.

Rochat, T., L. Bermúdez-Humarán, J.-J. Gratadoux, C. Fourage, C. Hoebler, G. Corthier, and P. Langella. 2007. Anti-inflammatory effects of Lactobacillus casei BL23 producing or not a manganesedependant catalase on DSS-induced colitis in mice. Microb. Cell Fact. $6: 22-32$.

Sanders, M. E., F. Guarner, R. Guerrant, P. R. Holt, E. M. Quigley, R. B. Sartor, P. M. Sherman, and E. A. Mayer. 2013. An update on the use and investigation of probiotics in health and disease. Gut 62:787-796.

Saxelin, M., A. Lassig, H. Karjalainen, S. Tynkkynen, A. Surakka, H. Vapaatalo, S. Järvenpää, R. Korpela, M. Mutanen, and K. Hatakka. 2010. Persistence of probiotic strains in the gastrointestinal tract when administered as capsules, yoghurt, or cheese. Int. J. Food Microbiol. 144:293-300.

Shinohara, K., Y. Ohashi, K. Kawasumi, A. Terada, and T. Fujisawa. 2010. Effect of apple intake on fecal microbiota and metabolites in humans. Anaerobe 16:510-515.

Siezen, R. J., B. Renckens, I. van Swam, S. Peters, R. van Kranenburg, M. Kleerebezem, and W. M. de Vos. 2005. Complete sequences of four plasmids of Lactococcus lactis ssp. cremoris SK11 reveal extensive adaptation to the dairy environment. Appl. Environ. Microbiol. 71:8371-8382.

Smith, T. J., D. Anderson, L. M. Margolis, A. Sikes, and A. J. Young. 2011. Persistence of Lactobacillus reuteri DSM17938 in the human intestinal tract: Response to consecutive and alternate-day supplementation. J. Am. Coll. Nutr. 30:259-264.

Tachon, S., J. Zhou, M. Keenan, R. Martin, and M. L. Marco. 2013. The intestinal microbiota in aged mice is modulated by dietary resistant starch and correlated with improvements in host responses. FEMS Microbiol. Ecol. 83:299-309.

Tannock, G. W., B. Lawley, K. Munro, S. Gowri Pathmanathan, S. J. Zhou, M. Makrides, R. A. Gibson, T. Sullivan, C. G. Prosser, D. Lowry, and A. J. Hodgkinson. 2013. Comparison of the compositions of the stool microbiotas of infants fed goat milk formula, cow milk-based formula, or breast milk. Appl. Environ. Microbiol. 79:3040-3048.

Turnbaugh, P. J., F. Bäckhed, L. Fulton, and J. I. Gordon. 2008. Dietinduced obesity is linked to marked but reversible alterations in the mouse distal gut microbiome. Cell Host Microbe 3:213-223.

Wu, G. D., J. Chen, C. Hoffmann, K. Bittinger, Y.-Y. Chen, S. A Keilbaugh, M. Bewtra, D. Knights, W. A. Walters, R. Knight, R. Sinha, E. Gilroy, K. Gupta, R. Baldassano, L. Nessel, H. Li, F. D. Bushman, and J. D. Lewis. 2011. Linking long-term dietary patterns with gut microbial enterotypes. Science 334:105-108.

Yu, W., K. Gillies, J. K. Kondo, J. R. Broadbent, and L. L. McKay. 1996. Loss of plasmid-mediated oligopeptide transport system in lactococci: Another reason for slow milk coagulation. Plasmid $35: 145-155$. 